\title{
¿Legados dictatoriales? \\ Instituciones y prácticas policiales entre pasado y presente en América del Sur
}

\author{
Dictatorial legacies? \\ Institutions and police practices between past and present in South America
}

Máximo Sozzo*

\begin{abstract}
Resumen: Este trabajo pretende abordar la cuestión de los legados dictatoriales en las instituciones y practicas policiales en América del Sur. Se identifican dos elementos fundamentales: la militarización y la marginalización de la ley. Luego, se exploran algunas de sus manifestaciones cruciales y como han sido enfrentadas en algunos contextos en el marco de las luchas políticas en torno a la transición a la democracia y los resultados que se han generado. Se utilizan ejemplos del caso de Argentina. Concluye con una reflexión sobre la cuestión de los legados dictatoriales, su relación con el pasado remoto y sus metamorfosis en las prácticas e instituciones policiales contemporáneas.
\end{abstract}

Palabras clave: Legados. Dictaduras. Policía. América del Sur.

Abstract: This paper aims to address the issue of dictatorial legacies in police institutions and practices in South America. Two key elements are identified: militarization and marginalization of the law. Then it explores some of its crucial manifestations and how they have been confronted in some contexts in the framework of the political struggles around the transition to democracy and the effects they have produced. Examples of Argentina are used with the hope to promote a comparative vision at the region. It concludes with a reflection on the dictatorial legacies, its relation with the remote past and its metamorphosis in the contemporary police institutions and practices.

Keywords: Legacies. Dictatorships. Police. South America.

* Doctor en Derecho por la la Universidad Nacional del Litoral (UNL, Santa Fe, Argentina), en dónde es profesor titular ordinario de Sociologia y Crminologia. Además es Adjunct Professor en la School of Justice de la Queensland University of Technology en Brisbane City, Australia $<$ msozzo80@gmail.com>.

Civitas, Porto Alegre, v. 16 , n. 4, p. 552-574, out.-dez. 2016 


\section{Introducción}

1. En América del Sur las experiencias dictatoriales atravesaron buena parte del siglo XX, en el que se alternaron con tentativos de construcción de regímenes democráticos más o menos duraderos y más o menos limitados por diversas causas. Por ejemplo, en Argentina, entre 1930 y 1983 se produjeron 6 golpes de estado y en 24 de esos 53 años existieron regímenes dictatoriales instaurados y gestionados por las fuerzas armadas, con apoyos de diversos sectores sociales. Las experiencias dictatoriales de 1966-1973 y 1976-1983 - con un breve y convulsionado interregno democrático - se caracterizaron - especialmente esta última - por unos niveles de brutalidad y crueldad extraordinarios - en comparación con los propios precedentes nacionales -, articulando niveles de violencia y represión a través del empleo de los aparatos del estado frente a la disidencia política que han generado su caracterización como la producción de un genocidio. Desde 1983 en adelante comenzó un proceso de transición a la democracia que no obstante sus múltiples obstáculos y limitaciones, no recayó en la imposición de un régimen político autoritario. Los ciclos y características de los regímenes dictatoriales en América del Sur durante el siglo XX han tenido fuertes variaciones. Pero desde fines de los años 1970 comenzaron simultáneamente estos procesos de transición a la democracia - que con rasgos muy disímiles - han sido uno de los elementos estructurantes de la historia reciente de la región - en Ecuador a partir de 1979, en Perú a partir de 1980, en Bolivia desde 1982, en Argentina desde 1983, en Brasil y Uruguay desde 1984 y en Chile desde 1990.

La relación entre las policías y los regímenes políticos dictatoriales en la región a lo largo del siglo XX ha tenido también un amplio grado de variación que vuelve difícil la realización de generalizaciones que atraviesen las fronteras espaciales y temporales. Esto se debe tanto a las organizaciones diversas de las instituciones policiales en cada país sudamericano - basta pensar en la oposición entre países federales como Brasil, Venezuela o Argentina y países unitarios como Bolivia, Perú, Chile, Uruguay o Ecuador - como a las características mismas de los regímenes dictatoriales, en sus diversos ciclos. Pero un elemento común que se encuentra presente en las experiencias dictatoriales es la fuerte "ocupación" por parte de las fuerzas armadas de las instituciones policiales, especialmente de sus cúpulas que pasaron a estar integradas por oficiales militares, gobernando su funcionamiento cotidiano por períodos prolongados e introduciendo cambios organizativos, normativos, culturales y prácticos que también persistieron en el tiempo, reforzando el carácter de "policía de estado" que colocaba como principal objetivo el 
mantenimiento del orden político y como principal blanco de actuación a la disidencia política, en un sentido amplio. En función de la duración variable de estas ocupaciones, se produjo un impacto más o menos fuerte en términos de militarización de las normativas, organizaciones, culturas y prácticas policiales que derramó más allá de los confines de lo que los regímenes dictatoriales definían como "delito político", desplegando sus efectos en torno a las actividades policiales en relación con el "delito común". Sin embargo, sería un error pensar que la militarización de las estructuras y actividades policiales se inaugura en la región con estas experiencias dictatoriales (Rico, 1997, p. 84; Sozzo, 2005, p. 185; Sain, 2008, p. 128-129). En realidad se inscribe en el mismo nacimiento de las policías que se inicia en el siglo XIX en el proceso de construcción de los estados modernos. Por ejemplo, en Argentina antes del primer golpe de estado por parte de las fuerzas armadas de 1930, la policía de la Provincia de Buenos Aires y, desde su creación en 1880, la policía de la capital federal - las más importantes en términos de estructura y personal en el marco de un contexto federal - tuvieron durante períodos prolongados como jefes a oficiales militares en actividad o retirados y además una parte importante de los policías eran ex-soldados - en 1908 representaban dos tercios del total del "personal de tropa" de la policía de la capital federal (RodriguezZappietro, 1999, p. 235). Algunos de estos oficiales militares, en tanto Jefes de Policía, produjeron profundas reformas destinadas a organizar la estructura y actividad policial en torno al modelo militar. Un ejemplo paradigmático en este sentido fue el coronel Ramón Falcón que fue jefe de la policía de la capital federal entre 1906 y 1909 (Rodriguez-Zappietro, 1999, p. 228-245; Kalmanowiecki, 2001, p. 200; Barreneche y Galeano, 2008, p. 104; para un abordaje específico de este momento ver Barry, 2010a; 2010b). En todo caso, como bien ha señalado Kalmanowiecki (2001, p. 197), esta militarización de la institución policial estuvo estructuralmente conectada ya desde el siglo XIX a la focalización de la actividad policial en el "enemigo político". Pero las ocupaciones militares durante las dictaduras militares elevaron dicho rasgo precedente y persistente a niveles paroxísticos. En el caso de Argentina, este salto cuantitativo y cualitativo se dio por, primera vez, luego del golpe de estado de 1955, acompañado por la fuerte penetración cultural de la doctrina de la seguridad nacional y no ceso de crecer en intensidad en las experiencias dictatoriales subsiguientes (Kalmanowiecki, 2001, p. 208; Andersen, 2001, p. 167-208; Galvani, 2007, p. 39-40; Montero, 2008). ${ }^{1}$

${ }^{1}$ En el caso de Chile, fue muy fuerte a partir del golpe de estado de 1973, traduciéndose en 1975 en el desplazamiento de la dependencia de la Policía de Investigaciones y Carabineros 
Otro elemento común, está vinculado a la paradójica marginalización del lugar de la ley en pensar y practicar la actividad policial, cuya misión se define tradicionalmente como hacer cumplir la ley, cumpliendo la ley. Los regímenes dictatoriales implicaron - de nuevo con diversa intensidad atravesando el tiempo y el espacio - una suspensión de los principios y reglas fundamentales del estado de derecho precedentemente declamados en textos constitucionales y legales. Las policías operaron en este marco más general en que dicha suspensión se combinaba con diversas modificaciones del "derecho vigente" producidas por las estructuras organizativas del poder dictatorial. Algunas de esas modificaciones se refirieron explícitamente a las estructuras y actividades policiales y alteraban los principios y reglas fundamentales del estado de derecho. En este marco, el vínculo con la ley para los actores policiales experimentó una suerte de flexibilización. En el ejemplo de Argentina, esto adquirió niveles paroxísticos durante la última dictadura militar (1976/1983) en que las estructuras y el personal policial participaron activamente en estrategias e intervenciones que violaban incluso la pretendida legalidad emanada del poder dictatorial, aun cuando organizadas y planificadas por el régimen mismo, desarrollando prácticas sistemáticas de represión extraordinariamente violenta contra la disidencia política - secuestros, torturas, asesinatos, desapariciones, supresión de identidad de niños, etc. -, en paralelo a las prácticas policiales oficiales, por lo general referidas al llamado "delito común". Estás vidas paralelas de la institución policial, a veces tenían un correlato en una división organizativa de segmentos y personal policiales que se ocupaban de ellas, pero en ciertos casos esto no era así, habilitando que los policías viajaran a través de estas dos dimensiones en su ocupación cotidiana y a través de largos períodos, dejando una fuerte marca en la construcción de la identidad policial. A través de estos viajes - pero también en función de un clima político y cultural más amplio dentro y fuera de la institución policial - la marginalización de la ley que adquirió un nivel extremo en la policía política "paralela" o "subterránea" invadió también las actividades policiales "oficializadas". Ejemplos sintomáticos de ello fueron la utilización masiva de la detención sin orden judicial por parte de la policía de calle fundada en la sospecha de que el individuo habría cometido o podría cometer un delito y la utilización masiva de ciertas formas de tortura a ciudadanos detenidos

al Ministerio de Defensa y el cambio de la definición normativa de esta última a partir de la reforma de su ley orgánica de institución civil a institución militar (Dammert, 2007, p. 119, 172-173, ver también Aguila y Maldonado, 1996; Rico, 1997, p. 87). En el caso de Brasil esto pasó durante la última dictadura militar que comenzó en 1964 y duró 21 años (Hinton, 2005, p. 81-82). 
por la sospecha de haber cometido un delito común y dirigidas a la obtención de una confesión en el marco del interrogatorio policial. (Andersen, 2001, p. 257-294). ${ }^{2}$ De nuevo, aquí se puede caer en el error de imaginar que esta marginalización de la ley en la estructuración de las actividades policiales ha sido gestada exclusivamente a partir de las experiencias dictatoriales. También aquí nos encontramos con un rasgo de larga duración que se hunde en el surgimiento mismo de las instituciones policiales desde el siglo XIX. Por ejemplo, en Argentina las prácticas policiales de detención sin orden judicial - a través de diversas instrumentos, como la detención por averiguación de domicilio o los edictos policiales - se daban en forma extraordinariamente frecuente desde la segunda mitad de siglo XIX en la policía de Buenos Aires y desde 1880, con su creación, en la Policía de la Capital Federal (Sozzo, 2008, p. 202-211). Pero las experiencias dictatoriales - especialmente aquellas más extremadamente represivas - elevaron este segundo elemento también a niveles paroxísticos. (Pinheiro, 1991; 2002; O’Donnell, 2002; Hinton, 2005, p. 70-80; Fruhling, 2009a, p. 468).

Este trabajo pretende abordar estos legados a partir de algunas de sus manifestaciones cruciales en la institución y actividad policial contemporáneas. ${ }^{3}$ También incluimos un análisis de episodios de enfrentamiento con estas manifestaciones cruciales de los legados de las dictaduras en la institución y la actividad policial durante la transición democrática, señalando sus efectos en el marco de los debates y luchas políticas en torno a la democratización policial. Vamos a explorar aquí sustantivamente el caso de Argentina. Pero confiamos que este trabajo puede ser útil para el desarrollo de una mirada comparativa en América del Sur.

2. Una de las manifestaciones cruciales de la militarización en algunas policías sudamericanas ha sido la construcción y mantenimiento de una estructura organizativa con una jerarquía muy fuerte fundada en la separación

\footnotetext{
${ }^{2}$ Para el caso de Chile, sobre la utilización constante de detenciones sin orden judicial durante la dictadura militar, ver Fruhling (2001, p. 28) y Dammert (2007, p. 127). Sobre las prácticas de tortura por parte de los policías durante la última dictadura militar en Brasil, ver el importante trabajo de Huggins y Haritos-Fatourus (1996), Huggins (2000), Huggins, Zimbardo, HaritosFatourus (2002).

${ }^{3}$ Hay otras áreas de los discursos y prácticas policiales en América del Sur en que estos legados se expresan de un modo claro y crucial que por razones de espacio no exploro en este ensayo. Es posible incluir allí: el uso de las facultades para detener ciudadanos sin un orden judicial, los mecanismos de educación policial diseñados y administrados independientemente por autoridades policiales, estrategias policiales tradicionales frente a la protesta policial, el involucramiento directo del personal militar en la actividad policial la absoluta predominancia de los mecanismos de control interno de la actividad policial por sobre cualquier tipo de dispositivo externo.
} 
de dos tipos de policías: oficiales y suboficiales. Cada uno de estos segmentos posee su propio proceso de reclutamiento - con requisitos diferentes -, educación - en espacios institucionales separados y con duraciones y características distintas - y carrera - con grados distintos y mecanismos de ascenso diferente. Esta separación es tajante. Eso hace que un suboficial no pueda ascender en la jerarquía sino hasta el grado máximo disponible dentro de su propio segmento, limitando sus aspiraciones y posibilidades profesionales. Se trata de una estructura de castas, en las que los suboficiales son definidos como policías de segunda clase, están destinados a posiciones y tareas subordinadas y constituyen la mayoría del personal policial. Esa separación resulta un eje muy fuerte de las relaciones de poder al interior de la institución policial, distribuyendo autoridad y obediencia.

Esta estructura organizativa ha sido impugnada en algunos contextos en el marco de la transición a la democracia, por considerarla incompatible con la idea de una burocracia estatal regida por principios de meritocracia en los que el desempeño sea el elemento fundamental en la distribución de posiciones y tareas. En el ejemplo de Argentina, en algunas jurisdicciones - recordemos que existen 23 policías provinciales y cuatro fuerzas de seguridad federales - dicha separación ha sido abolida en los últimos años en el marco de procesos de reforma policial más o menos ambiciosos. En el marco de lo que constituyó uno de los primeros procesos de esta índole, en la Provincia de Buenos Aires en 2004 se sancionó una nueva legislación policial, Ley 13201 - que derogó dos textos normativos sancionados por la dictadura militar en 1980 - que unificó la jerarquía policial en nueve grados - los dos primeros para oficiales de dirección, los dos segundos para oficiales de conducción y los cinco restantes para oficiales de supervisión y policiales. Esta ley fue modificada más recientemente en 2009, por la Ley 13982, en un contexto contrareformista. Si bien no se restableció la separación tajante, se crearon dos "subescalafones", uno de "comando" - con diez grados - y otro "general" - con siete grados -, estando el segundo subordinado al primero, con una lógica similar a la diferenciación entre oficiales y suboficiales, aunque sin el obstáculo para que quienes tienen un grado en el subescalafon general puedan ascender al subescalafón comando. En la Provincia de Santa Fe en 2006 se produjo un cambio similar, a través de la sanción de la ley 12521 de personas policial que derogo un texto normativo de 1972 sancionado también durante un gobierno dictatorial. Esta reforma abolió la diferenciación entre oficiales y suboficiales e instaló una única estructura jerárquica compuesta por 10 grados. Ahora bien, en el mismo país existen muchas otras instituciones policiales en las que este tipo de separación tajante 
sigue estando presente. Se desataca el caso de la policía federal Argentina - el segundo cuerpo policial en volumen de personal policial de Argentina, luego de la Policía de la Provincia de Buenos Aires - cuya ley orgánica actualmente vigente fue sancionada por la dictadura militar en 1979. Se establece aquí una diferenciación estricta entre "personal superior" y "personal subalterno". ${ }^{4}$

3. Un segundo terreno en el que es posible visualizar una manifestación del legado de las dictaduras en las policías sudamericanas contemporáneas está vinculado a la difusión de ciertas representaciones en la cultura policial en torno a la persona que comete un delito y el modo de enfrentarla. Pero también la presencia, reversible e indisociablemente, de determinadas representaciones en torno a lo que significa ser policía, en este caso ancladas incluso en la normativa policial. ${ }^{5}$

Por un lado - y como anticipábamos más arriba -, la militarización de la institución policial como un proceso que precede y excede las experiencias dictatoriales estuvo fuertemente vinculada en su formación histórica con la colocación como objetivo privilegiado de la actividad policial, jerarquizado sobre otras tareas, de la guerra contra un "enemigo interno", definido en términos políticos, el "subversivo", que se construyó como un pariente cercano del "enemigo externo", en torno al que se edificaron las fuerzas armadas. Esa imagen fue mutando en sus encarnaciones a través del tiempo y del espacio en la región. Desde los años 1950 y en relación con las experiencias dictatoriales, se produjo en los escenarios sudamericanos un salto cualitativo con la difusión de la llamada Doctrina de la Seguridad Nacional. Esa doctrina fue un fuerte elemento homogeneizador que atravesó las fronteras nacionales y que le dio contenidos semejantes a la representación del "enemigo interno", en gran medida producidos y difundidos desde instituciones estatales de países centrales - Francia y Estados Unidos. Se lo identifico como un disidente político, oculto y omnipresente, comprometido con la producción de la revolución social, en relación con los múltiples y variados procesos y movimientos de esta índole que atravesaron la región durante la segunda mitad del siglo XX, pero que eran sintéticamente comprendidos en la genérica referencia a la "amenaza comunista". Este enemigo interno - como el externo sobre cuya base estaba moldeado - era construido como un "otro" irreconciliable con el "nosotros" que

\footnotetext{
${ }^{4}$ Para el caso de Argentinas, sobre el significado y consecuencias de esta estructura organizacional, ver CELS-HRW (1998, p. 84-87), Tiscornia y Oliveira (1998, p. 161-162), Sain (2008, p. 144-145), Glanc (2014, p. 484).

${ }^{5}$ La difusión de estas representaciones no significa que no existan imágenes alternativas que también estén presentes en las culturas policiales contemporáneas, que presentan cierto grado de fragmentación y heterogeneidad (Frederic, 2009, p. 67).
} 
debía ser neutralizado y en el límite eliminado, para defender un orden social considerado justo y valioso. Esta representación fue crucial en el despliegue, en general, de las estrategias represivas por parte de los regímenes dictatoriales $y$, en particular, en el involucramiento activo de las fuerzas policiales en la producción de violaciones sistemáticas y brutales a los derechos humanos (Montero, 2008). Ahora bien, más allá de la referencia al "subversivo", ciertos componentes de esta representación difundida en la cultura policial durante las experiencias dictatoriales - pero que, como decíamos, se inscribía en un surco que las precedía - derramó fuera de sus confines, invadiendo también la imagen del "delincuente" con respecto al cual se desenvolvía buena parte de la actividad policial "oficial". 6

En el proceso de transición a la democracia la finalidad de la lucha contra el enemigo interno comprendido como el subversivo fue perdiendo peso en la cultura e institución policial. Se trató de un proceso lento y progresivo y en algunos casos, aun inacabado. ${ }^{7}$ Ahora bien, la lucha contra el enemigo interno comprendido como el delincuente, con una fuerte dosis de otredad, aunque variable según los diferentes contextos y con respecto a diferentes sectores del mundo del delito común, pero siempre involucrando una devaluación de su carácter de ciudadano, se ha colocado como finalidad y tarea en el centro de la cultura policial contemporánea. Esto ha sido reforzado y amplificado en los escenarios nacionales en los que se han instalado fuerte y recurrentemente crisis de inseguridad frente al delito común como eje del debate público y político durante los años 1990 y 2000 y que han visto simultáneamente un progresivo auge del lenguaje de la mano dura entre las elites políticas y mediáticas. Esta representación, por supuesto, se nutre también de otras fuentes culturales, pero tiene innegablemente algunos resabios de aquel pasado remoto y reciente. ${ }^{8}$

\footnotetext{
${ }^{6}$ Desde mi punto de vista, fue importante a este respecto el encuentro con otra fuente de representaciones acerca del delincuente, la criminología positivista, fuertemente difundida en las policías de la región desde el último cuarto del siglo XIX en adelante. Esta otra fuente cultural construía también una otredad en torno al delincuente, con distintos grados de radicalidad, en unos términos psicológicos y sociales, sobre la base de las ideas de anormalidad y peligrosidad. Ver Sozzo (2005, p. 188-191).

${ }^{7}$ Ha habido en diversos contextos escándalos nacidos del descubrimiento de ciertas actividades de "policía política" llevadas adelante por segmentos policiales una vez avanzados estos procesos de transición, en los años 1990 y 2000, pero que no están vinculados a la persistencia de aquellas imágenes acerca de la "amenaza comunista" -aunque en algunos casos han tenido como blanco a diversos movimientos sociales-, sino al despliegue de actividades de "inteligencia" por parte de las cúpulas policiales en el intercambio que mantienen con las elites políticas en el juego de la democracia realmente existente, como prueba de su utilidad en las relaciones de poder más amplias - sobre ese tipo de intercambio en el caso argentino, ver Sain (2008, p. 29-40; p. 125-129) y Sozzo, Gonzalez, Montero (2010, p. 310-316).

${ }^{8}$ Ver para el caso argentino, Tiscornia y Olivera (1992; 1998, p. 160-161), Sain (2008, p. 139), Bonner (2009, p. 227-228); Frederic (2009, p. 80-81); Glanc (2014, p. 486-487). En general,
} 
Por otro lado, es posible rastrear legados de la experiencia dictatorial en las policías sudamericanas contemporáneas en la forma en que se representa ser policía, tanto en la normativa como en la cultura policial, vinculada a su vez a la presencia del lenguaje de la guerra contra el delincuente como enemigo interior. Persiste una imagen promovida oficialmente del policía como héroe y mártir, en gran medida moldeada sobre la figura del soldado. Esta imagen lo distingue y separa del resto de los ciudadanos. La misma se ancla, antes que nada, en una esfera de derechos y deberes específicos que le corresponden por ser miembro de la institución policial, el llamado - en algunas jurisdicciones - "estado policial". Este estado policial implica un estatuto jurídico diferencial, que se extiende incluso una vez que el policía se ha retirado. Por un lado, el policía está autorizado a hacer cosas que un ciudadano típicamente no puede hacer como, por ejemplo, detener a otro ciudadano por la sospecha de que ha cometido un delito o que está por cometerlo. Pero también está impedido de hacer cosas que un ciudadano típicamente puede hacer como, por ejemplo, agremiarse para defender sus derechos como empleado público. En el marco de ese estatuto jurídico diferencial un lugar fundamental es ocupado por las obligaciones de portar el arma de fuego reglamentaria tanto estando de servicio como estando de franco, así como el deber de intervenir en todas las situaciones en que la función policial así lo requiera tanto estando de franco como estando de servicio - e incluso habiéndose retirado. Y debe hacerlo siempre en forma valiente, sin lugar a la denominada "debilidad moral" - en muchos casos tipificada como una falta o infracción en el régimen disciplinario. Se es policía las 24 horas del día y los 365 días del año y serlo implica intervenir decididamente todas las veces que sea necesario, para alcanzar el reconocimiento como héroe o, en su defecto, mártir - lo que implica en muchas instituciones policiales el automático ascenso postmortem. Se trata de la piedra basal en torno a la que oficialmente se pretende gestar la identidad policial, marcada por la abnegación, el sacrifico y el altruismo, que se traduciría en la producción de un "espíritu de cuerpo" en relación con los que se encuentran en la misma posición y visiblemente en la portación del uniforme. ${ }^{9}$

resulta este un tema importante para la indagación empírica en el futuro sobre la cultural policial en la region. Algunos elementos interesantes al respecto pueden verse para Argentina en Seri (2012, p. 981-992); Garriga Zucal (2013a; 2013b); Montero (2013) y Ghiberto (2013).

${ }_{9}$ Para el caso de Argentina, ver al respecto Tiscornia y Olivera (1998, p. 166-167), CELS-HRW (1998, p. 88-91), Chevigny (2002, p. 64-65), Sozzo et al. (2005a, p. 104-106), Sozzo (2005, p. 191-192), Galvani (2007, p. 76, 79, 87), Frederic (2009, p. 69-70, 76), Galeano (2011), Seri (2012, p. 94-97), Galvani y Mouzo (2013, p. 101-105), Glanc (2014, p. 485-487). 
En algunos escenarios, se ha buscado confrontar este tipo de imágenes en la cultura policial - entre otros de sus componentes - en el marco de iniciativas de reforma que se han orientado a modificar la estructura, funcionamiento y contenidos de las instancias de educación policial. Por ejemplo, en Argentina esto ha estado presente en aquellas experiencias reformistas de mayor alcance. En la Provincia de Santa Fe, en 2004 se sancionó al respecto la ley 12333 que creó como entidad autárquica en la órbita del Ministerio de Gobierno, Justicia y Culto, el Instituto de Seguridad Pública (Isep). La creación del Isep implicó el cierre de todas las viejas instancias educativas de la policía provincial. El Isep es autónomo con respecto a la cúpula policial. Los ingresantes no adquieren carácter de funcionarios policiales, aunque reciben una beca por parte del estado para estudiar las dos carreras disponibles, de distinta duración. El director del Isep se elige mediante concurso público de antecedentes y oposición y tiene una estabilidad en el cargo de cinco años. Luego de la primera gestión de un funcionario no policial dicha posición ha sido asumida por un policía retirado. Asimismo se estableció la conformación de un "Consejo Interinstitucional" integrado por representantes de diversas instituciones estatales, incluyendo el Ministerio de Educación. Este Consejo es el órgano de conducción de la política educativa del Isep, de acuerdo al texto legal. También se modificaron la estructura curricular y los contenidos de los cursos. Un lugar importante en dicha modificación ha sido la introducción de contenidos vinculados a la protección y promoción de los derechos humanos. También se ha dado formalmente la supresión de aspectos comúnmente ligados a la militarización en la educación policial - desfiles, uniformes, régimen de internado, etc. Sólo a partir del año 2009 el Isep ha tenido sus primeros egresados. Las indagaciones empíricas acerca de su funcionamiento - realizadas en ese momento - muestran un cuadro alejado del discurso normativo y oficial, con una cierta subsistencia de elementos del modelo tradicional de educación policial, con predominio de docentes que son policías retirados o en actividad y que ocupan su posición con una alta dosis de informalidad e irregularidad, con la presencia en la cotidianeidad de rasgos en la relación entre instructores y alumnos típicos de la disciplina de las viejas escuelas de policía y con fuertes déficits de recursos humanos y materiales (Ugolini, 2011, p. 101-118). Ahora bien, como ya ha sido sostenido en otros escenarios, la investigación empírica en este mismo contexto provincial muestra que en las representaciones de los policías "de calle" la educación policial tiene asignado un peso menor en relación a la experiencia y la práctica en la construcción de un saber hacer y una identidad policial (Gonzalez, 2012, p. 58-61; Ghiberto, 2013, p. 118-121). De todas maneras, resulta aún pendiente una evaluación empírica del impacto 
concreto de este cambio en las instancias educativas policiales - con todas sus ambigüedades - en las imágenes acerca del delito y el ser y quehacer policial entre quienes han pasado por ellas en estos últimos años. ${ }^{10}$

Siguiendo con el ejemplo de Argentina, se han dado también en algunas jurisdicciones con respecto al "estado policial" algunos intentos de modificación puntual que si bien no han desmantelado su existencia en la normativa - y por tanto su impacto en la cultura-policial, han enfrentado algunos de sus componentes considerados más disvaliosos en términos simbólicos y prácticos. Esto ha ocurrido con la obligación de portar el arma de fuego reglamentaria aun estando de franco o retirado, considerada uno de los factores - entre otros - del alto nivel de abuso de la fuerza en las policías argentinas, tanto por académicos como por organizaciones de derechos humanos. Así en la policía federal Argentina en 1999 se modificó el Reglamento General de Armas y Tiro (Orden del Día 115) y se estableció que el arma reglamentaria solo debía portarse durante el servicio policial, siendo luego un derecho del policía hacerlo durante la situación de franco o de retiro. Del mismo modo, en la Provincia de Buenos Aires en 2004 la nueva ley de personal policial volvió la portación del arma reglamentaria una facultad para el policía que se encuentra de franco, incluyendo la necesidad de la previa autorización del superior. Con la contrarreforma del año 2009, se eliminó el requerimiento de la autorización del superior. En la Provincia de Santa Fe, la ley de personal policial del año 2006 estableció la obligación de portar el arma de fuego exclusivamente durante la prestación del servicio y para los policías con "autoridad policial" que integran el "escalafón general".

También se han dado cambios normativos en alguna jurisdicción para anular la obligación de intervenir estando de franco o retirado en situaciones en las que se esté cometiendo un delito, volviéndola una facultad del agente policial. De este modo se ha establecido en la ley de personal policial de la Provincia de Buenos Aires sancionada en 2004, lo que se ha mantenido en la contrarreforma del 2009. No ha habido cambios en esta dirección en las otras jurisdicciones apenas mencionadas. Como se observa, este tipo de cambios normativos no han impedido completamente la continuidad de las prácticas tradicionales de portación del arma de fuego las 24 horas ni de intervención estando de franco o retirado, aun cuando han dejado de hacerlas obligatorias.

\footnotetext{
${ }^{10}$ En otras jurisdicciones argentinas se han dado cambios que tienen algunos puntos en común con el aquí referido, como en las provincias de Buenos Aires y Mendoza y a nivel federal, en la Policía Federal, pero las indagaciones empíricas acerca de su dinámica y efectos se encuentran también aún pendientes en gran medida (Varela et al., 2008, p. 49-59; Arslanian, 2008, p. 129-167; Frederic, 2009, p. 60-64; 2013; Sirimarco, 2013).
} 
Como en otras manifestaciones de los legados dictatoriales, la presencia de intentos de cambiar algunos elementos de estas representaciones difundidas acerca del delincuente y del policía en la cultura policial han estado presentes en algunas jurisdicciones durante la transición a la democracia. Pero no en otras. Y en las que emergieron parecen haber tenido resultados muy modestos, dejando esta herencia aún sólida en los discursos y prácticas policiales contemporáneos.

4. Un tercer aspecto en donde el legado de las experiencias dictatoriales se presenta muy nítidamente en las policías sudamericanas contemporáneas es el extraordinario peso del frecuente y múltiple uso de la violencia en el desarrollo de sus prácticas cotidianas. Por supuesto, no resultan idénticas las frecuencias y modalidades atravesando las fronteras nacionales e incluso dentro de un mismo contexto nacional existe, en ciertos casos, amplio nivel de variación entre provincias, estados, regiones o ciudades o entre el ámbito urbano y el ámbito rural. Esto puede dar lugar a debates acerca de los niveles presentes en cada caso desde una mirada comparativa - ver, por ejemplo, la comparación entre Chile y Argentina de Fuentes (2005). Resulta difícil generar esas contrastaciones a partir de indicadores válidos y confiables dada la escasísima información oficial que producen las autoridades policiales y políticas acerca del despliegue de la violencia policial y su heterogeneidad atravesando las fronteras, además de la extraordinaria cantidad y variedad de formas de su ejercicio que quedan ocultas por esos escasos ejercicios de registración oficial. Sin embargo, parece existir un consenso en la literatura sociológica y criminológica acerca de que el exceso o abuso en el uso de la violencia por parte de las policías sudamericanas es una constante observable en muchos casos nacionales.

A su vez, existen ciertas formas de su despliegue que se repiten en diversos escenarios. En primer lugar, los casos de muertes de ciudadanos por el uso de armas de fuego por parte de policías que constituyen ejecuciones ilegales - aun cuando los agentes frecuentemente inventan a posteriori una situación de "enfrentamiento" para producir su encubrimiento. En segundo lugar, los casos de desapariciones de ciudadanos por parte de agentes policiales, menos frecuentes que la forma anterior pero igualmente presente. Ambas formas de despliegue suelen nacer de la dinámica de redes de ilegalidad con participación y protección policial. En tercer lugar, los casos de ciudadanos muertos y heridos por el uso de armas de fuego por parte de policías en situaciones que han nacido de la comisión de un delito pero en que el uso de la violencia ha sido evidentemente excesivo e inadecuado - y que incluso 
tienen en ciertos casos como destinatario no a los supuestos autores del delito sino a terceros presentes en dicha situación. En cuarto lugar, los casos de ciudadanos muertos y heridos por el uso de la violencia - incluyéndola la utilización de armas de fuego - por parte de policías que actúan en forma evidentemente excesiva e inadecuada en el contexto de manifestaciones y protestas sociales. En quinto lugar, los casos de muertes, torturas y lesiones de ciudadanos privados de su libertad por parte de la policía, frecuentemente en móviles y espacios policiales - a su vez originados en causas y dinámicas diferentes, desde arrancar la confesión de un delito a forzar la participación del destinatario en una actividad delictiva protegida policialmente. Por último - pero no por ello menos importante en función de su amplia extensión - los casos de hostigamiento por parte de agentes policiales a ciertos grupos socialmente desventajados en el espacio público, que involucran el uso de la violencia de "baja intensidad" - por lo general sin el empleo de armas de fuego - en algunos casos vinculado a la lógica de redes de ilegalidad con participación y protección policial y en otros casos, a la construcción de autoridad por parte del agente policial manifestada en su capacidad de denigrar y degradar al destinatario.

Más allá de la multiplicidad de sus formas, una constante observada en la región es que los destinatarios de la violencia policial suelen ser grupos sociales desfavorecidos, con escasa capacidad de reclamo social en las relaciones de poder contemporáneas - jóvenes, varones, pobres, residentes en áreas urbanas marginadas. Este peso extraordinario de la violencia en la actividad policial cotidiana - especialmente de los policías "de calle" - en algunos casos implica desplegar las mismas técnicas empleadas por las instituciones policiales durante las experiencias dictatoriales - por ejemplo, los distintos tipos de tortura, como el empleo de la picana eléctrica. Y se ve articulado en buena parte con las representaciones ancladas en la normativa y la cultura policial, a las que nos referimos en el punto anterior como fuertemente vinculadas a dicho pasado, en torno a la guerra contra el delincuente como enemigo interno a neutralizar y al carácter del policía como ciudadano especial y separado, potencial héroe y mártir, fuertemente ligado en su construcción histórica a su capacidad de usar la fuerza - y especialmente el arma de fuego. Pero también, como hemos señalado más arriba, está funcionalmente conectado en algunas de sus formas con la dinámica de las múltiples redes de ilegalidad que han nacido y se han desarrollado con participación y protección policial. En este plano se observa una manifestación evidente del legado de la marginalización de la ley en la actividad policial como otro costado del legado de las experiencias 
dictatoriales en las policías de América del Sur, al que nos referíamos en la primera sección de este artículo. ${ }^{11}$

En los diversos contextos nacionales de América del Sur ha habido tentativos por parte de diversos actores estatales y no estatales por tratar de influir en la realidad del despliegue de la violencia policial de diversas formas, impulsando iniciativas reformistas que tratan de evitar los abusos y excesos que incluso se han tematizado en la agenda pública y política como un legado del autoritarismo del que es preciso desembarazarse en el proceso de democratización. En el ejemplo de Argentina, todas las iniciativas reformistas que hemos analizado en este trabajo hasta aquí se han legitimado como formas de intervenir para disminuir los niveles de violencia policial, desde los cambios en la estructura organizativa y normativa de las fuerzas policiales, a las modificaciones en las instancias y dinámicas de la educación policial. E incluso ha habido otras acciones en esta dirección. En diciembre de 2010 y a partir de una serie de escándalos públicos en torno a casos de violencia policial protagonizados por la policía federal Argentina, la presidenta creó el Ministerio de Seguridad de la Nación. Se generó entonces un discurso acerca de la necesidad de democratizar las políticas de seguridad a nivel nacional, enfatizando la necesidad de asumir el "gobierno político" de esta temática, empleando para ello como clave la noción de "seguridad democrática" que una serie de organizaciones sociales, académicos y políticos venían promoviendo en sus esfuerzos reformistas (Sain, 2012a, p. 57-58; 2012b, p. 85-86, 2013, p. 288-290). La creación del Ministerio significó el fortalecimiento de un cuerpo administrativo y político dedicado a esta temática, implicando un cambio que modificó cuantitativa y cualitativamente la intervención de los actores políticos en la toma de decisiones que rompía en cierta medida con la tradición de delegación política y autonomía policial que se había venido dando desde el inicio de la transición a la democracia en Argentina. Como consecuencia de cambios en la composición del ministerio dicho impulso inicial se desinfló completamente desde el 2013 (Sain, 2012a, p. 46-47, 58; 2012b, p. 93-293; 2013, p. 293; CELS, 2013, p. 238-254; Sozzo, 2014; p. 27-30; Bonner, 2015, p. 1-3). Pero en este marco se dispuso la creación

\footnotetext{
${ }^{11}$ En el caso de Argentina, la literatura sociológica y criminológica sobre la cuestión de la violencia policial es muy vasta. Ha sido muy valioso al respecto el trabajo desde los años 1980 del Centro de Estudios Legales y Sociales (ver al respecto, los Informes Anuales sobre la Situación de los Derechos Humanos en Argentina y especialmente, CELS-HRW (1998, p. 79-237) y Tiscornia (1999; 2000). Ver también sobre diversas dimensiones del fenómeno: Sozzo (2002); Pita (2010; 2011); Montero (2007; 2010; 2013); Linzer et al. (2007); Sain (2008, p. 154-160); Frederic (2009; 2011); Bonner (2009); Seghezzo (2010); Mouzo et al. (2010); Rangugni (2010); Rodriguez Gamez (2011); Garriga Zucal (2013a); Lorenz (2013); Glanc (2014, p. 486-487).
} 
del Programa de Uso Racional de la Fuerza y Armas de Fuego que buscaba reducir el número de muertos y heridos generados por la actividad policial a través de medidas de control, reentrenamiento y bienestar policial para las diversas fuerzas de seguridad federales (CELS, 2013, p. 257, 259-260). No ha habido una evaluación empírica acerca de los resultados obtenidos por esta iniciativa concreta, pero resultó una de las primeras de su tipo en este contexto nacional. Resulta difícil construir una valoración acerca de si estas medidas e iniciativas reformistas produjeron efectivamente una reducción de los niveles de violencia policial en las diversas jurisdicciones en las que se llevaron adelante. En gran medida, esto se debe a la ausencia de producción de información oficial incluso sobre los fenómenos más evidentes de despliegue de la fuerza física policial. El Centro de Estudios Legales y Sociales para el área metropolitana de Buenos Aires (ciudad de Buenos Aires y gran Buenos Aires) ha registrado - a partir del uso de la fuente periodística ante la ausencia de información oficial - una caída en el número de ciudadanos muertos por parte de las fuerzas policiales desde el pico del turbulento año 2001 - en que se llegó a 317 muertes - para llegar en 2006 a 86 ciudadanos, casi la mitad de las muertes registradas en 1995 (157), primer año de la serie. Se mantuvo en niveles similares hasta 2008 pero a partir de ese año el volumen volvió a crecer. En el último año disponible, 2012, el número llegó a 107 - que de todas formas significó un 33\% menos que en 1995 y un 66\% menos que en el pico de 2001 (CELS, 2013, p. 135). De todas maneras, la fuente de esta información así como las múltiples otras formas de violencia policial que no abarca este indicador vuelve necesario ser cautelosos al respecto.

5. Hemos argumentado que existen en las policías sudamericanas contemporáneas dos elementos cruciales que se pueden vincular a las experiencias de las dictaduras militares recientes: la militarización y la marginalización de la ley. Exploramos dichos elementos a través de tres terrenos - entre otros - en los que se vuelven particularmente visibles: a) la diferenciación en la organización policial de dos tipos de agentes policiales (oficiales y suboficiales) en un sistema de castas, que resulta crucial en la constitución de las relaciones de poder a su interior; b) la difusión fuerte en la cultura policial de una imagen del delincuente como enemigo interno contra el que hay que luchar y del policía como un agente separado y diferente del resto de los ciudadanos, en función de un "estado" enraizado en la normativa policial que lo vuelve tal las 24 horas y lo impulsa a intervenir siempre que sea necesario, decidida y valientemente, promoviendo su carácter de héroe y mártir; c) la extraordinaria presencia de variadas formas de violencia 
policial en la actividad policial cotidiana, dirigidas a los grupos sociales desfavorecidos, tanto para mantener redes de ilegalidad con participación y protección policial como para reforzar la construcción de un estilo de autoridad en los encuentros con los ciudadanos.

Estos dos elementos no son exactamente dos caras de la misma moneda y es por eso que la extensión y desarrollo de cada uno de ellos en contextos particulares puede ser desigual. Pero tienen una fuerte afinidad y se pueden apoyar recíprocamente. Estos dos elementos no son únicos de las policías de esta región. Podemos claramente encontrar trazos de ellos también en otros escenarios en los que no hubo experiencias dictatoriales en el pasado reciente. Sin embargo, su grado extremo y marcada combinación en América del Sur puede pensarse como relacionada con la fuerte presencia de este tipo de régimen político.

En uno de los pocos trabajos que se interrogan directa y centralmente acerca de los legados autoritarios en la institución y actividad policiales en América del Sur - en una clave comparativa -, Mark Ungar y Anthony Pereira (2004, p. 1) señalan críticamente que algunos investigadores han construido una mirada sobre las diversas dinámicas y procesos que podrían ser caracterizadas de este modo que se funda en la consideración de un período breve, enfatizando en forma desmedida el peso de las experiencias de las recientes dictaduras militares. Frente a ello abogan por considerarlas un fenómeno de larga duración que se hunde en los procesos mismos de construcción de los diversos estados en la región desde el siglo XIX. Coincidentemente, en este trabajo hemos planteado que los diversos legados que hemos identificado y analizado no han sido inventados en las últimas experiencias dictatoriales sino que provienen de un pasado remoto. Pero creo que debemos enfatizar que durante dicho pasado reciente, fueron elevados a su forma paroxística y por medio de ese desenvolvimiento, produjeron un impacto aún más fuerte y persistente en nuestro presente. Ungar y Pereira (2004, p. 5) parecen sugerir que se trata de legados de un "estado autoritario" que resultaría independiente de los regímenes políticos formalmente adoptados pero en cuya caracterización no avanzan significativamente en su trabajo. Considero más útil pensar estas persistencias a partir de la noción del autoritarismo como estrategia gubernamental con su propia racionalidad, tecnologías y prácticas de ejercicio del poder, que ha sido muy fuerte a lo largo de la historia de América del Sur, con diferentes grados de extensión y fortaleza en relación a diferentes problemas, en distintos momentos y lugares, pero siempre parte constitutiva del orden social y político (Sozzo, 2005, p. 181-192). 
Glanc (2014, p. 481) en un trabajo reciente en el que plantea a las formas de la violencia policial contemporáneas ejercitadas por la policía federal en la Argentina como un legado del pasado - en este caso, más bien identificado como reciente y relacionado con la última experiencia dictatorial (2014, p. 483), acierta al precisar que pensarlo de este modo no implica considerarlo una mera repetición de lo que nos ha precedido. En este trabajo hemos mostrado como las diferentes manifestaciones que hemos identificado de los legados autoritarios en las instituciones y actividades policiales sudamericanas han sido objeto en el marco de la transición a la democracia de debates y luchas por parte de diversos actores - estatales y no estatales - en determinadas jurisdicciones y coyunturas. Utilizando ejemplos del contexto argentino ${ }^{12}$ hemos mostrado como en torno a algunos de ellos se han producido cambios significativos, nunca en la medida de las ambiciones proclamadas por los impulsores de las iniciativas pero suficientemente contundentes para considerarlos tales - aun cuando resulte difícil considerar que lo heredado del pasado remoto y reciente ha desparecido en este escenario. Como bien señala, en términos generales, Robert Castel: "El pasado no se repite a sí mismo en el presente, pero el presente juega e innova usando el legado del pasado" (Castel, 1994, p. 238). Estos legados dictatoriales están continuamente siendo objeto de una metamorphosis en nuestro presente. El hecho de que estas transacciones entre herencia e innovación existan debe considerarse, al mismo tiempo, como un elemento de la realidad contemporánea que debe ser descripto e interpretado y que debe ser tomado en cuenta en nuestros ejercicios de inventiva etica y política.

\footnotetext{
${ }^{12}$ Ungar y Pereira en su estudio comparativo acerca de los legados autoritarios en las policías de Argentina, Chile, Uruguay y Brasil plantean que este escenario es aquel en el que en el marco del proceso de transición a la democracia se ha producido el nivel más amplio de reformas policiales de diverso tipo que han tratado de lidiar con dicha herencia (2004, p. 5-7). Dicha caracterización parece ser en ciertos momentos un tanto ingenua pues se asumen cambios normativos y retóricos como si fueran cambios prácticos efectivamente ocurridos, que hubieran sido evaluados empíricamente en forma independiente (Ungar y Pereira, 2004, p. 12-19) - esto vuelve a aflorar en un trabajo ulterior de Ungar (2009) dedicado exclusivamente a la reforma policial en Argentina. Por supuesto, esto no implica desconocer la importancia de las mutaciones simbólicas pero sí significa tener en mente que no necesariamente implican transformaciones en los modos de actuar. Sin embargo, es preciso reconocer que en este punto el caso argentino que aquí hemos analizado puede presentar diferencias tangibles con respecto a las otras sociedades sudamericanas que experimentaron recientemente dictaduras militares.
} 


\section{Referencias}

AGUILA, Ernesto; MALDONADO, Carlos. Orden público en el Chile del siglo XX: trayectoria de la una policía militarizada. In: P. Waldman (org.). Justicia en la calle. Ensayos sobre la policía en América Latina. Medellín: Konrad Adenauer Stiftung, Ciedla, Isla, 1996. p. 73-97.

ANDERSEN, Martin. La policía. Pasado, presente y propuestas para el futuro. Buenos Aires: Sudamericana, 2001.

ARSLANIAN, León Carlos. Un cambio posible: delito, inseguridad y reforma policial en la Provincia de Buenos Aires. Buenos Aires: Edhasa, 2008.

BARRENECHE, Osvaldo; GALEANO, Diego. Notas sobre las reformas policiales en Argentina: Siglos XIX y XX. Cuadernos de Seguridad, v. 8, p. 73-114, 2008.

BARRY, Viviana. Policía y reclutamiento: hombres y organización policial en Buenos Aires, 1880 y 1910. Horizontes y Convergencias, 2010a <http://horizontesyc.com. $\operatorname{ar} / ? \mathrm{p}=3524>$ (6 dic. 2016).

BARRY, Viviana. Carrera e identidad policial. Medios fundamentales para su construcción en la Capital Federal a inicios del siglo XX. Horizontes y Convergencias, 2010 b <http://horizontesyc.com.ar/?p=3521> (6 dic. 2016).

BONNER, Michelle. State discourses, police violence and democratization in Argentina. Bulletin of Latin American Research, v. 28, n. 2, p. 227-245, $2009<10.1111 /$ j.1470-9856.2008.00270.x>.

BONNER, Michelle.Rethinking debates on media and police reform in Argentina. Policing and Society, v. 26, n. 8, p. 925-943, $2015<$ tandfonline.com/doi/pdf/10.1080/ 10439463.2014.993632)> (26 ene. 2015).

CASTEL, Robert. Problematization as a way of reading history. In: J. Goldstein (org.). Foucault and the writing of history. Cambridge: Cambridge University Press, 1994. p. 237-252.

CELS-HRW. La inseguridad policial. Violencia de las fuerzas de seguridad en la Argentina. Buenos Aires: Eudeba, 1998.

CELS. Derechos humanos en Argentina. Informe 2013. Buenos Aires: Siglo XXI, 2013.

CHEVIGNY, Paul. Definiendo el rol de la policía en América Latina. In: P. Pinheiro G. O’ Donnell, G. e J. Mendez (orgs.). La (in)efectividad de la ley y la exclusión en América Latina. Buenos Aires: Paidos, 2002. p. 59-78.

DAMMERT, Lucía. Perspectivas y dilemas de la seguridad ciudadana en América Latina. Quito: Flacso-Municipio Metropolitano de Quito, 2007.

FRUHLING, Hugo. Las estrategias policiales frente a la inseguridad ciudadana en Chile. In: A. Candina; H. Fruhling (orgs.). Policía, sociedad y estado. Modernización y reforma policial en América del Sur. Santiago de Chile: CED, 2001.

FRUHLING, Hugo. Research on Latin American police: where do we go from here? Police Practice and Research: An international Journal, v. 10, n. 5-6, p. 465-481, 2009a. 
FRUHLING, Hugo. Recent police reform in Latin America. In: Niels Uldriks (org.). Policing insecurity. Police reform, security and human rights in Latin America. Landham: Lexington, 2009b. p. 21-47.

FREDERIC, Sabina. Los usos de la fuerza pública: debates sobre policías y militares en las ciencias sociales en la Argentina. Buenos Aires: UNGS/Biblioteca Nacional, 2009.

FREDERIC, Sabina. Oficio policial y usos de la fuerza pública: aproximaciones al estudio de la policía de la provincia de Buenos Aires. In: E. Bohoslavsky; G. Soprano (orgs). Un estado con rostro humano. Funcionarios e instituciones estatales en Argentina (de 1880 a la actualidad). Buenos Aires: Prometeo, 2011. p. 281-308.

FREDERIC, Sabina. La formación policial en cuestión: impugnación, valoración y transmisión de los "saber hacer" policiales. In: J. Zucal Garriga Zucal; M. Galvani, B. Renoldi; S. Frederic (orgs.). De armas llevar. Estudios socioantropológicos sobre los quehaceres de policías y de las fuerzas de seguridad. La Plata: Ediciones de Periodismo y Comunicación ; Facultad de Periodismo y Comunicación Social de la Universidad Nacional de La Plata, 2013. p. 271-304.

FUENTES, Claudio. Contesting the iron fist. Advocacy networks and police violence in democratic Argentina and Chile. New York: Routledge, 2005.

GALEANO, Diego. Caídos en el cumplimiento del deber. Notas sobre la construcción del heroísmo policial. In: D. Galeano; G. Kaminsky. Mirada (de) uniforme. Historia y critica de la razón policial. Buenos Aires: Editorial Teseo, 2011. p. 185-219.

GALVANI, Mariana. La marca de la gorra. Un análisis de la policía federal. Buenos Aires: Capital Intelectual, 2007.

GALVANI, Mariana; MOUZO, Karina. Locos y mártires. Un análisis comparativo entre dos fuerzas de seguridad argentinas. In: J. Garriga Zucal; M. Galvani; B. Renoldi; S. Frederic (orgs.). De armas llevar. Estudios socioantropológicos sobre los quehaceres de policías y de las fuerzas de seguridad. La Plata: Ediciones de Periodismo y Comunicación; Facultad de Periodismo y Comunicación Social de la Universidad Nacional de La Plata, 2013. p. 89-114.

GARRIGA ZUCAL, José. Usos y representaciones del "olfato policial" entre los miembros de la policía bonaerense. Dilemas, v. 6, n. 3, p. 489-509, 2013 a.

GARRIGA ZUCAL. "Un correctivo". Violencia y respecto en el mundo policial. In J. Garriga Zucal, M. Galvani, B. Renoldi e S. Frederic (orgs.). De armas llevar. Estudios socioantropológicos sobre los quehaceres de policías y de las fuerzas de seguridad. La Plata: Ediciones de Periodismo y Comunicación; Facultad de Periodismo y Comunicación Social de la Universidad Nacional de La Plata, 2013b. p. 147-172.

GLANC, Laura. Caught between soldiers and police officers: police violence in contemporary Argentina. Policing and Society, v. 24, n. 4, p. 479-496, 2014.

GHIBERTO, Luciana. Cultura policial y estereotipos. Exploración sociológica en la ciudad de Santa Fe. Delito y Sociedad, n. 35, p. 113-134, 2013.

GONZÁLEZ, Gustavo. Mapeando el trabajo policial. La in/experiencia en el oficio como variable de diferenciación. Delito y Sociedad, n. 32, p. 55-85, 2012. 
HINTON, Mercedes. A distant reality: Democratic policing in Argentina and Brazil. Criminal Justice, v. 5, n. 1, p. 75-100, 2005.

HUGGINS, Martha; HARITOS-FATOURUS, Mika. Conciencia torturada: secretos y moralidades en la violencia policial brasilera. In: Peter Waldmann (org.). Justicia en la calle. Ensayos sobre la policía en América Latina. Medellín: Biblioteca Jurídica Dike, 1996.

HUGGINS, Martha. Legacies of authoritarianism. Brazilian torturers and murderers reformulation of memory. Latin American Perspectives, v. 27, n. 2, p. 57-78, 2000.

HUGGINS, Martha; ZIMBARDO, Philip; HARITOS-FATOURUS, Mika. Violence workers. Police torturers and murderers reconstruct brazilian atrocieties. Berkeley: University of California Press, 2002.

KALMANOWIECKI, Laura. Police, politics and repression in modern Argentina. In: C. Aguirre y Robert Baffington. Reconstructing criminality in Latin America. Jaguar Books: Delaware, 2001. p. 195-218.

LINZER, Maximiliano; LÓPEZ, Diego; MALCOLM, Florencia; MOUZO, Karina; ORTIZ MALDONADO, Natalia; RECEPTER, Celina; RIOS, Alina; RODRÍGUEZ, Gabriela; SEGHEZZO, Gabriela. Aproximaciones al uso de la fuerza letal por parte de las fuerzas de seguridad contra personas menores de 21 años en el Amba entre 1996 y 2004. Delito y Sociedad, n. 23, p. 137-154, 2007.

LORENZ, Mariana. Enseñar a tirar. Aprender a morir. In: J. Garriga Zucal; M. Galvani; B. Renoldi; S. Frederic (orgs.). De armas llevar. Estudios socioantropológicos sobre los quehaceres de policías y de las fuerzas de seguridad. La Plata: Ediciones de Periodismo y Comunicación; Facultad de Periodismo y Comunicación Social de la Universidad Nacional de La Plata, 2013. p. 173-208.

MONTERO, Augusto. Policía y violencia. Apuntes comparativos sobre el lugar de la fuerza física en la definición del objeto de la sociología de la policía. Delito y Sociedad, v. 1, n. 23, p. 59-87, 2007.

MONTERO, Augusto.. Las policías y la doctrina de la seguridad nacional en Argentina. Primera aproximación. In: G. Bombini; R. Bergalli e I. Rivera Beiras. Violencia y sistema penal. Buenos Aires: Editores del Puerto, 2008. p. 265-290.

MONTERO, Augusto. Niñez, exclusión social y "propiedad policial” en la ciudad de Santa Fe. Delito y Sociedad, v. 2, n. 30, p. 33-54, 2010.

MONTERO, Augusto. ¿Con las manos atadas? Indagaciones sobre motivos y audiencias paras las violencias policiales contra los niños en la ciudad de Santa Fe. Delito y Sociedad, v. 36, n. 22, p. 76-102, 2013.

MOUZO, Karina; RIOS, Alina; RODRIGUEZ, Gabriela; SEGHEZZO, Gabriela. Hacer morir. Prácticas policiales y la (re)inscripción del poder soberano en la economía del biopoder. In: V. Rangugni (org.). A la inseguridad la hacemos entre todos. Buenos Aires: Hekht Libros, 2010. p. 215-230.

O’DONNELL, Guillermo. Las poliarquías y la (in)efectividad de la ley en América Latina. In: P. Pinheiro; G. O’Donnell; J. Mendez (orgs.). La (in)efectividad de la ley y la exclusión en América Latina. Buenos Aires: Paidós, 2002. p. 305-336. 
PINHEIRO, Paulo Sérgio. Police and political crisis: the case of the military police. In: M. Huggins (org.). Vigilantism and the state in modern Latin America. Praeger: New York, 1991. p. 167-188.

PINHEIRO, Paulo Sérgio. La efectividad de la ley y los desfavorecidos en América Latina. In: P. Pinheiro; G. O’Donnell; J. Mendez (orgs.). La (in)efectividad de la ley y la exclusión en América Latina. Buenos Aires, Paidós: 2002. p. 16-36.

PITA, María Victoria. Formas de vivir y formas de morir. El activismo contra la violencia policial. Buenos Aires: CELS-Editores del Puerto, 2010.

PITA, María Victoria. Violencia policial y demandas de justicia: algunas formas de protesta popular. In: Mariano Gutierrez (org.). Populismo punitivo y justicia expresiva. Buenos Aires: Fabian di Placido Editor, 2011.

RANGUGNI, Victoria. Prácticas policiales y gobierno de la (in)seguridad en Argentina. In: Victoria Rangugni (org.). A la inseguridad la hacemos entre todos. Buenos Aires: Hekht Libros, 2010. p. 231-252

RICO, José. Justicia penal y transición democrática en América Latina. México D.F.: Siglo XXI, 1997.

RODRIGUEZ, Adolfo; ZAPPIETRO, Eugenio. Historia de la policía federal Argentina. Buenos Aires: Editorial Policial, 1999.

RODRIGUEZ GAMES, Nicolás. Estado del arte respecto del uso policial de la fuerza. In: C. Ales (org.). Regulación y control del uso policial de la fuerza y la coerción en Argentina. Bueno Aires: Ministerio de Seguridad de la Nación, Tinker Foundation and Universidad Nacional de Tres de Febrero, 2011. p. 21-72.

SAIN, Marcelo. El leviatán azul. Policía y política en Argentina. Buenos Aires: Siglo XXI Editores, 2008.

SAIN, Marcelo. Es la política, estúpido. El gobierno federal frente a la reforma policial en Argentina. Comunes, v. 1, p. 35-64, 2012a.

SAIN, Marcelo. Un paso adelante, dos pasos atrás. El kirchnerismo ante la cuestión policial. Delito y Sociedad, v. 34, n. 21, p. 67-99, 2012 b.

SAIN, Marcelo. La oscilación. Los vaivenes de la reforma del sector seguridad en la Argentina reciente. In: Carlos Basombrio (org.). ¿A dónde vamos? Análisis de las políticas públicas de seguridad ciudadana en América Latina. Buenos Aires: Woodrow Wilson International Center for Scholars-UMET, 2013. p. 267-300.

SEGHEZZO, Gabriela. Entre los derechos humanos y la (in)seguridad: modos de construcción de la "violencia policial" en las ciencias sociales. In: Mariana Galvani; Karina Mouzo; Natalia Maldonado; Victoria Rangugni; Celina Recpter; Alina Lis Rios; Gabriela Rodríguez; Gabriela Seghezzo. A la inseguridad la hacemos entre todos. Buenos Aires: Hekht Libros, 2010. p. 51-74.

SERI, Guillermina. Seguridad: crime, police power and democracy in Argentina. New York and London: Continuum, 2012.

SIRIMARCO, Mariana. Reformas policiales y narrativas institucionales en Argentina: renombrando escuelas de policía. Dados: Revista de Ciências Sociais, v. 56, n. 3 , p. $605-633,2013<10.1590 /$ S0011-52582013000300005>. 
SOZZO, Máximo. Usos de la violencia y construcción de la autoridad policial en la Argentina. In S. Gayol; G. Kessler (orgs.). Violencias, delitos y justicias en la Argentina. Buenos Aires: Universidad Nacional de General Sarmiento-Manantial, 2002. p. 225-258.

SOZZO, Máximo. Policía, violencia, democracia. Nota genealógica. In: M. Sozzo (org.). Policía, violencia y democracia. Exploraciones sociológicas. Santa Fe: UNL Ediciones, 2005. p. 161-208.

SOZZO, Máximo. Inseguridad, prevención y policía. Quito: Flacso-Municipio Metropolitano de Quito, 2008.

SOZZO, Máximo. Delito común, inseguridad y respuestas estatales. Inercias e innovación durante la década kirchnerista a nivel nacional. Cuestiones de Sociología, n. 10, p. 23-38, 2014.

SOZZO, Máximo. ¿Más allá de la disciplina policial? Transformaciones de los mecanismos de control de la actividad policial en la Provincia de Santa Fe. In: M. Sozzo (dir.). Policía, violencia y democracia. Exploraciones sociológicas. Santa Fe: UNL Ediciones, 2005a. p. 85-124.

SOZZO, Máximo. Política, policía y violencia en la Provincia de Santa Fe. In: M. Sozzo (dir.). Policía, violencia y democracia. Exploraciones sociológicas. Santa Fe: UNL Ediciones, 2005b. p. 15-67.

SOZZO, Máximo; GONZÁlEZ, Gustavo; MONTERO, Augusto. ¿Reformar la policía? Representaciones y opiniones de policías en la Provincia de Santa Fe. In: M. Sozzo (coord.). Por una sociología crítica del control social. Ensayos en honor a Juan S. Pegoraro. Buenos Aires: Editores del Puerto, 2010.

TISCORNIA, Sofía; OLIVEIRA, Alicia. Estructura y prácticas de las policías en la Argentina. Las Redes de la Ilegalidad. In: Hugo Fruhling (org.). Control democrático en el mantenimiento de la seguridad interior. Santiago de Chile: CED, 1998. p. 157-174.

TISCORNIA, Sofía. Violencia policial en capital federal y gran Buenos Aires. Cuestiones metodológicas y análisis de datos. In: M. Sozzo (org.). Seguridad urbana: nuevos problemas, nuevos enfoques. Santa Fe: Editorial UNL, 1999.

TISCORNIA, Sofía. Violencia policial, derechos humanos y reforma policial. Delito y Sociedad, v. 1, n. 14, p. 9-22, 2000.

UGOLINI, Augustina. Transformaciones recientes de la formación policial en la Provincia de Santa Fe. In: C. Ales (org.). Regulación y control del uso policial de la fuerza y la coerción en Argentina. Bueno Aires: Ministerio de Seguridad de la Nación, Tinker Foundation y Universidad Nacional de Tres de Febrero, 2011. p. $93-122$.

UNGAR, Mark; PEREIRA, Anthony. The persistence of mano dura. Authoritarian legacy and policing in Brazil and the Southern Cone. In: K. Hite; P. Cesarini (orgs.). Authoritarian legacies and democracy in Latin America and southern Europe. Notre Dame: University of Notre Dame, 2004. p. 263-304. 
UNGAR, Mark. Police reform in Argentina: public security versus human rights. In: Niels Uldriks (org.). Policing insecurity. Police reform, security and human rights in Latin America. Landham: Lexington, 2009. p. 169-196.

VARELA, Cristián. La educación policial: estudio de los sistemas educativos policiales de la region NEA y de las fuerzas de seguridad y cuerpos policiales federales. Buenos Aires: Pnud, Secretaria de Seguridad Interior, 2008.

Autor correspondiente:

Máximo Sozzo

San Jeronimo 14272 Piso Depto C

CP 3000 Santa Fe, Argentina

Recibido el: 10 jul. 2016.

Aprobado el: 25 ago. 2016. 